when occurring in atypical age groups.-We are, etc.,

ANDREW G. CUDWORTH A. Ellis David Lewis Northern Hospital,
Liverpool

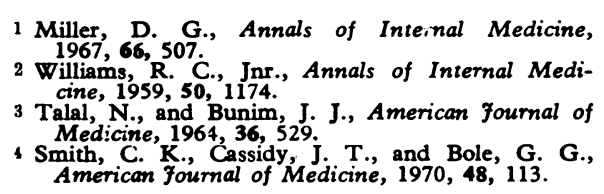

\section{Monitoring of Carbon Dioxide in} Anaesthesia

SIR,-I read with great interest Dr. B. James's letter on "Monitoring of Carbon Dioxide in Anaesthesia" (24 June, p. 770). May I mention the use of yet another apparatus which is quite different in principle from that of Dr. James. Based on the property of $\mathrm{CO}_{2}$ to absorb infra-red light of a particular wavelength, Godart's capno graph measures and records the concentration of $\mathrm{CO}_{2}$ rapidly and continuously. For more than a decade this apparatus has been in routine use in Academisch Ziekenhuis (University Hospital), Utrecht.-I am, etc.,

Institute of Anaesthesiology,

SAJIDUL QUADIR Academisch Ziekenhuis,

1 Smalhout, B., Opuscula Medica, 1970, 15, 129.

\section{Febrile Convulsions in Eariy Childhood}

SIR,-Having pointed out (10 June, p. 631) that mesial temporal (Ammon's horn) sclerosis and the epilepsy to which it commonly gives rise are a common sequel to a severe febrile convulsion in infancy, may I be permitted to make some comments on the leading article on "Febrile Convulsions in Early Childhood" (p. 608). You stress the benign characteristics of febrile convulsions in childhood, whereas my purpose was to indicate that these are not always present.

It would appear that the incidence of febrile convulsion may be as high as 50 to 70 infants per thousand. ${ }^{1}$ They are therefore common. However, to divide them arbitrarily into two groups: simple febrile convulsions, and epileptic seizures precipitated by fever, as Livingstone does ${ }^{2} 3$ is fallacious, because both are epileptic phenomena, both occur in the same age periods in infancy, both have a similar incidence of epilepsy in the family history, and both probably have the same aetiology. ${ }^{1}$ The chief difference is the severity of the attack, and as one is milder it carries a better prognosis. However, even the milder seizures are frequently followed by later recurrences. ${ }^{3-5}$

A febrile convulsion is an epileptic seizure occurring in the context of a febrile illness which is not primarily of cerebral origin, and thus is not meningitis or encephalitis. Authorities are not agreed on the duration of a febrile convulsion before it should be placed in the second group rather than the first. Your leading article stated an upper limit of ten minutes, but others allow periods as long at thirty minutes." It is not surprising that the convulsions of longer duration should sometimes have features of a focal nature (for example, hemiparesis) or be more likely to show E.E.G. abnormalities. However, in my experience, even after the more severe febrile seizures, the E.E.G.s may appear normal.

It is the contention of my colleagues and myself (10 June, p. 631) that a prolonged febrile convulsion in infancy (of the order of half an hour or more) may lead to hypoxic changes in such structures as the hippocampus, amygdala, and parahippocampal gyrus, which result in the lesion formerly called Ammon's horn (hippocampal) sclerosis, but which we prefer to term mesial temporal sclerosis. This lesion in its turn becomes a frequent cause of habitual temporal lobe epilepsy in children (and in adults), and it is commonly unilateral.

The proportion of infants who have severe as compared with mild febrile convulsions is high. Ounsted ${ }^{1}$ reported that in a personally observed series of 438 infants with febrile convulsions $33(8 \%)$ convulsed to death, while 120 of the 405 survivors (30\%) developed drug-resistant habitual seizures. Livingston, whom your leading article quotes, stated in a later report ${ }^{3}$ that, of 622 infants seen at the Johns Hopkins Hospital with their first febrile convulsive seizure and subsequently followed up for at least 15 years, 256 came within the category of simple febrile convulsions, and only seven of these (3\%) subsequently developed recurring febrile seizures. However, of the remaining 366 infants, 355 (97\%) subsequently developed various types of seizure unassociated with fever.

The sequelae of a febrile convulsion are thus related to its severity (as measured by its duration) rather than to any apparent differences in aetiology. A mild convulsion may be the precursor of a more severe one. In reviewing the histories of patients with epilepsy due to mesial temporal sclerosis, I have been struck by the long and inexplicable delays that at times occurred before treatment to cut short the convulsion had been started. That is why I wrote "No doctor called to see a convulsing infant should leave that infant until the attack is over." (10 June, p. 631). Only by taking prompt measures to cut short a continuing convulsion will the subsequent incidence of epilepsy caused by mesial temporal sclerosis be reduced.-I am, etc.,

MURRAy A. FALCONER

Neurosu:gical Unit of Guy's, Maudsley,

and King's College Hospitals,

1 Ounsted, C., in Recent Advances in Paediatrics, ed. D. Gairdner and $D_{\text {. }}$

2 Livingstone, $S$. The Diagnosis and Treatment of Convulsive Disorders in Children, Springfield, Illinois, Thomas, 1954.

3 Livingston, S., Development Medicine and Child Neurology, $1968,10.374$.
Millichap, . S., Febrile Convulsions, New York, McMillan, 1968.

Rodin, E., A., The Prognosis of Patients with

\section{Urinary Calculi and Ulcerative Colitis}

SIR,-I read with interest the article by Professor R. C. Bennett and Mr. E. S. R. Hughes (27 May, p. 494). In earlier reports of renal stone formation occurring with greater frequency in patients with chronic ulcerative colitis ${ }^{1-3}$ and particularly in those patients who have undergone ileostomy, although it has usually been stated that these patients form uric acid stones scrutiny of the published data reveals that as many formed calcium-containing stones as formed uric acid stones. I have previously postulated a mechanism which explains the increased liability to either type of stone in these patients. ${ }^{4}$

There is a considerable amount of evidence that a relationship exists between the level of urinary sodium and the occurrence of renal stones.4 $\mathrm{My}$ previously reported studies suggest that it is the urinary sodium/ calcium or the urinary sodium/uric acid ratio respectively which is the key-relation, and that an inverse relationship exists between the ratio and the liability to stone formation. It has been shown ${ }^{6} 7$ that patients who have undergone ileostomy for chronic ulcerative colitis generally have a very low urinary output of sodium, in some instances as low as $10 \mathrm{mEq}$ a day (the average output of urinary sodium in my normal controls is $210 \mathrm{mEq}$ a day). There is no evidence that the urinary excretion of calcium, or uric acid, is altered. The urinary sodium/ calcium or urinary sodium/uric acid ratio could be expected to parallel this reduction in urinary sodium and thereby increase the liability to stone formation.-I am, etc.,

\section{ModLIN}

Renal Stone Clinic,

Groote Schuur Hospital,

1 Deren, J. J., Porush, J. G., Levitt, M. F., and Khilnani, M. T., Annals of Internal Medicine, $1962,56,843$.
Maratka, Z., and Nedbal, J., Gut, 1964, 5, 3. 3 Bennett, R.' C., and Jepson, R. P., Australian and
New Zealand fournal of Surgery, 1966/1967, Modlin, M., in Proceedings of the Renal Stone Research Symposium, ed. A. Hodgkinson 5 Modlin, M., Annals of the Royal College of Surgeons of England, 1967, 40, 155 .

, and Skyring, A.P., A. M., Chirnside, A., Hill, G. L., Pope,
G., and Stewart, M. K., Lancet, 2, 740 .

\section{Treating Incontinence Electrically}

SIR,-It is encouraging to see that the B.M.F. is maintaining interest in newer methods for treating these unfortunate patients. However, I wish to correct some impressions created by your leading article (17 June, p. 670). Although it was stated that Hopkinson is the only author to claim cures for electrical treatment, I have reported similar results. ${ }^{1-\uparrow}$ Further, experience in the last three years has led me to offer the implant electrode to patients requiring long-term stimulation. Why change to an implant electrode? It is more accurately positioned and more powerful. It is more acceptable socially than either a vaginal or anal electrode, and causes less discomfort. The external electrode stimulators currently available may be difficult to retain during strenuous activities.

When considering success rates it should be remembered that many patients treated in the specialist centres have had not one but several unsuccessful conventional operations before stimulation was attempted. If patients were referred earlier for the less drastic treatment by stimulation there would be more muscle and less scar tissue, with a resultant improvement in performance. In this context, it is not generally realized that the implant operation is a relatively minor procedure with few complications. For example, using basically the suprapubic approach demonstrated to me by Mr. K. P. S. 
Caldwell, I have had no case of sepsis in a series of 21 implant operations. One stimulator became faulty and required replacement; one frail patient suffered wound dehiscence but responded to resuture with no sepsis problems. The results are far from discouraging.

Your leader refers to difficulty in predicting success, and quotes my work as supporting L. Edwards in showing that no objective method is available. This is not the case. My paper at Exeter demonstrated that the standard technique then employed elsewher was unreliable, and described a reliable diagnostic and prognostic procedure, developed with David Rowan, principal physicist, Regional Department of Physics and Bio Engineering, my co-worker. We employ a urethral pressure profile measurement coupled with continuous intravesica pressure measurement, and are satisfied that the technique is reliable. ${ }^{56}$ Individuals who show a deteriorating urethral profile with increasing bladder volume can be expected to respond to pelvic floor stimulation. Successful control of incontinence by an external electrode is also a valuable guide for the use of an implant electrode. Our policy is to offer an implant to any patient who requires long-term stimulation for control Some of these implanted patients have subsequently become "cured"-that is, now are dry without stimulation some months after the operation. As to the disappointment suffered by a patient when a device is less successful than expected, this is no greater than after more drastic but unsuccessful major repair procedures.

Our experience indicates that an easy, reliable prognostic technique is available, and that patients who respond to an external stimulator but require long-term treatment should be offered an implant stimulator.

May I also give the correct title of our new society listed in the references as "European Continence Society." This should be International Continence Society (I.C.S.).

I wish to thank Mr. L. S. Scott for his encouragement in this work.

-I am, etc.,

Department of Urology,
Victoria Infirmary,

Glasgow

ERIC S. GLEN

1 Glen, E. S., British Medical fournal, 1970, 2, 650 Glen, E. S., British fournal of Surgery, 1971, 58, 3 Glen, E. S., Fournal of Pediatric Surgery, 1971, 4 6len, E. S., Scottish Medical fournal, 1971, 16, 120 .

Glen, E. S., Rowan, D. B:ological Engineering

5 Glen, E. S., Rowan, 4 Meciety 46th Scientific Meting, 1972 , Liverpool. Americal Urological Association, 1972, Washington D.C.

\section{School Refusa}

SIR,-Dr. Lionel Hersov (8 July, p. 102) gives a omprehensive survey of the complex problems of school failure in general and school phobia in particular. As he implies, school phobia is not a good term, but a better one is hard to come by.

A group of children who need special attention and who are, perhaps, increasing in number are the timid, inadequate 11 year-olds, usually not very able, transferring from junior to senior school. They come from the relatively well-structured environment of the small junior school, usually with the same teacher throughout the year and with little movement about the school
In the large comprehensive school they have to cope with as many teachers as subjects, have to find their way about the buildings, and, unlike the neighbourhood quality of their junior school, will have to make relationships with a mass of children from different schools and neighbourhoods. Their common complaint is "I got lost, I get confused" and some of these children give up before the end of their first day. To identify this group before entry may be difficult, but perhaps this could be helped by having a reception-type class where a sorting out process would go on during the first term and a better adjustment made to what will be, to some children, a rather overwhelming experience.

Regarding treatment, day patient care can often be effective providing as it does the necessary hospital support and teaching, while maintaining the child in his home and neighbourhood.-I am, etc.,

\section{G. L. Davies}

Departrent of Child and Family Psychiatry,

t. Luke's Hosp:tal,

Middlesb:ough

\section{Problems with Asthma}

SIR,-Drs. F. O. Wells and C. J. Stewart (1 July, p. 37) have demonstrated some interesting problems in managing their fatal case of asthma. Both practitioner and physician seem clear that infection was not of prime importance. Similarly the only demonstrable allergy, to Candida albicans, was probably the result of earlier treatment, although multifactorial, psychogenic factors are agreed to be particularly important.

Dr. Wells described his patient's ambivalence towards work. Did this attitude characterize his other relationships? Certainly there are grounds for saying that he became ambivalent, if not covertly hostile, to his doctors (lack of confidence, refusal of treatment, uncooperative). Nor was this owing to their lack of concern for his illness.

It can be reasonably assumed that he found open discussion of his angry feelings too painful or dangerous; he resorted to denial, and subconsciously to sadomasochistic displacement, not only towards his doctors, but more important, on to his own body in breathing distress. This reaction resembles the more obviously sadomasochistic behaviour, the syndrome of delicate self cutting, in that any unsupported effort to resolve interpersonal difficulties by separate activity brings on acute anxiety and a recurrence of overt illness. ${ }^{1}$ Denial of personal problems resulted in the patient visiting an ophthalmologist when a psychiatrist would have been appropriate.

Bastiaans $^{2}$ has suggested that we pay particular attention to frustrated drives leading to unresolved aggressive feelings and regressive behaviour. However, little has been described of this patient's real life roles and his fantasied ideals. Psychosomatic asthmatics may conform to the psychoanalytic stereotypes, ${ }^{3}$ but often their difficulties are unique. They often feel unescapably tied to a set of impossible parental or marita attitudes and relationships. ${ }^{4}$ They feel suffocated and entrapped, often by their own ideals. These problems become buried as they become conditioned by stress to fear of wheezing and ambivalent fear of death, the tension of which contributes to further wheezing. This aspect is well treated by behaviour therapy. ${ }^{56}$

My plea is that we strive constantly to wear two hats in psychosomatic disease ${ }^{7}$ medical awareness and psychosocial awareness. Between the acute episodes is the opportunity to know the human being in his life-situation.-I am, etc.,

\section{A. R. Dewsbury}

New Cross Hospital

Wolverhampton

Pao, P., British fournal of Psychology, 1969, 42, 195. 1969, 13, 307.

to Psychiatry. London, E. S.

Livingstone, 1968. Psychosomatic Medicine, 1960, 22, 127 . oore, M.,

Philipp, R. L., Wilde, G. J. S., and Day, J. H. Fournal of Pychosomatic Research, 1972, 16, 193. Williams, D. A., Lewis-Fang, E., Rees, L.,
Jacobs, J., and Thomas, A., Acta Allergologica,
1958, 12, 376.

\section{Diabetic Amyotrophy}

Sir,-Dr. A. Singer (15 April, p. 170) suggests that chronic occlusive peripheral vascular disease might have been directly responsible for the muscle wasting seen in the patients with diabetic amyotrophy who formed the basis of our follow-up study (11 March, p. 656). The evidence does no support such a contention. Firstly, there was little evidence of peripheral vascular disease. None of the 12 patients complained of intermittent claudication, and none had trophic changes in the legs. Five patients, including the one with the most severe muscle wasting, had normal peripheral pulses; one had three out of four foot pulses palpable, and two had both dorsalis pedis pulses palpable though no posterior tibial pulse. In three cases the records were incomplete.

Secondly, the electrophysiological evidence, which we presented, clearly demonstrated that the wasting and weakness were neurogenic in origin with signs of muscle denervation. The slowing of motor conduction velocity and absence of lateral popliteal nerve action potentials were further proof of the presence of peripheral neuropathy in our patients. There is therefore no reason to suggest that the muscle wasting was a direct trophic effect of muscle ischaemia.

In published studies of patients with severe chronic occlusive peripheral vascular disease, ${ }^{1-3}$ muscle wasting is not common and when present can usually be attributed to an ischaemic neuropathy.-We are, etc.

\section{J. G. HaRrisos}

National Hocpital,

E. B. CASEY

Department of Rheumatology and Physical Medicine, Middlesex Hospital,

1 Hutchinson, E. C., and Liversedge, L. A. Quarterly fournal of Medicine, 1956, 25, 267. 2 Miglietta, O., Archives of Neurology, 1966, 14,

3 Eames, R. E., and Lange, L. S., fournal of 30,215 .

\section{Large Doses of Fluphenazine Enanthate}

SIR.,-I read with interest the correspondence concerning large doses of fluphenazine enanthate and would like to comment 